\title{
Determination of the limiting values of the laser parameters to heat treatment of powder carbon steels surface
}

\author{
Svetlana Oglezneva ${ }^{1, *}$, Evgeny Morozov ${ }^{1}$ and Evgeny Usynin ${ }^{1}$ \\ ${ }^{1}$ Perm National Research Polytechnic University, 614990, Perm, Russia
}

\begin{abstract}
The microstructure and microhardness of the surface layer of powder steels PA-ZhGr with different porosity are studied in comparison with cast steel U10 after laser treatment (LT) with a $1 \mathrm{~kW}$ fiber laser in argon. Using thermal modeling, the geometric dimensions of the laser exposure zones formed in the area of the laser exposure were calculated and experimentally confirmed, and the mechanisms of their formation were proposed. The boundary values of the integral criterion for the parameters of laser influence for the heat treatment of carbon powder steels are established.
\end{abstract}

\section{Introduction}

Increasing the wear resistance of the surface of products is one of the urgent problems in mechanical engineering. This problem is effectively solved by creating functionally graded materials by changing the structure and properties of surface layers via laser [1, 2], which are increasingly being included in technological processes, along with methods such as thermal, chemical-thermal [2], diffusion [3], plasma [4-6], etc.

The result of the laser hardening is a high surface hardness as compared with the untreated, reduced friction coefficient, increasing the load capacity of the surface layer and other parameters.

Laser hardening of materials is achieved by local heating of a surface area under the influence of radiation and subsequent cooling of this area at high speed (laser hardening) as a result of heat dissipation deep into the metal [1, 7].

An analysis of the literature shows that most studies of laser exposure cover its effect on cast steels [8-13], and laser processing of powder products is usually performed to reduce surface porosity, to obtain coatings to restore parts [14-15] or deposit metal powders [1617]. Since the structure and physical properties of powder alloys differ from cast alloys (primarily, due to the presence of pores), it is necessary to establish optimal processing conditions for hardening the surface of powder steels with a laser, the main of which are the density of laser radiation power and the speed of spot movement laser [18-19].

\footnotetext{
* Corresponding author: director@pm.pstu.ac.ru
} 


\section{ICMTMTE 2019}

The purpose of the work is to study the effect of laser processing parameters on the microstructure and microhardness of the surface layer of carbon powder steel with different porosities.

\section{Materials and research methods}

Laser surface treatment was carried out on carbon steel samples containing 1\% carbon - PAZhGr powder steels with porosity of $4 \%, 8 \%$ and $10 \%$, as well as for comparison with cast (non-porous) U10 steel. Samples of powder steels were prepared by powder metallurgy from iron powder and colloidal graphite. The powders were mixed in a mixer with a shifted axis of rotation, pressed in a mold under a pressure of $400 \mathrm{MPa}$, then annealed in a vacuum furnace at a temperature of $900{ }^{\circ} \mathrm{C}$, re-compacted in a mold under a pressure of 500 or $550 \mathrm{MPa}$ and finally sintered in a vacuum at a temperature of $1150{ }^{\circ} \mathrm{C}$. Laser surface treatment was carried out on samples in the form of parallelepipeds of 25x25x200 mm using an industrial additive manufacturing machine Optomec LENS 850-R with a $1 \mathrm{~kW}$ fiber laser in argon. Samples were mounted on an aluminum plate for better heat dissipation.

For a full factorial experiment [20] 9 processing modes were used (table 1). The main varied parameters - power density $\mathrm{W}$ (encoded $\mathrm{x}_{1}$ ) and beam velocity $\mathrm{v}$ (encoded $\mathrm{x}_{2}$ ):

$$
W=\frac{P}{S},
$$

where $\mathrm{P}$ is the laser power, $\mathrm{S}$ is the spot area, which was calculated as

$$
S=\pi \cdot d^{2}
$$

where $\mathrm{d}$ is the diameter of the laser spot.

Table 1. Laser treatment processing modes for $\mathrm{d}=2 \mathrm{~mm}$.

\begin{tabular}{|c|c|c|c|}
\hline$\#$ & $\begin{array}{c}\text { Мощность P, } \\
\text { W }\end{array}$ & $\begin{array}{c}\text { Power Density W, } \\
\mathrm{kW} / \mathrm{sm}^{2}\end{array}$ & $\begin{array}{c}\text { Beam velocity v, } \\
\mathrm{cm} / \mathrm{c}\end{array}$ \\
\hline 1 & 251 & 8 & 0,8 \\
\hline 2 & 502 & 16 & 0,8 \\
\hline 3 & 251 & 8 & 1,2 \\
\hline 4 & 502 & 16 & 1,2 \\
\hline 5 & 376 & 12 & 0,8 \\
\hline 6 & 376 & 12 & 1,2 \\
\hline 7 & 251 & 8 & 1 \\
\hline 8 & 502 & 16 & 1 \\
\hline 9 & 376 & 12 & 1 \\
\hline
\end{tabular}

The laser beam spot diameter $d$ during laser processing was taken equal to $1.5 ; 2 ; 2.5$ and $4 \mathrm{~mm}$. Microhardness was measured according to GOST 9450-76 on a Knoop/Vickers Tester 402MVD hardness tester on a microsection made transverse to a single laser quenching track in the center of the thermal influence zone with a pitch of $75 \mu \mathrm{m}$ from the surface. 
The study of the microstructure and the measurement of the geometric parameters of the exposure zone were carried out with an Axiovert 40 Mat optical microscope with an increase of 5-50 times on non-etched and etched in nital microsections.

To obtain a set of parameters affecting the formation of cracks, we used the integral laser processing criterion, combining the laser radiation power $\mathrm{P}$, diameter $\mathrm{d}$, and the velocity of movement $\mathrm{v}$ of the laser spot:

$$
P /(d \cdot v)^{0.4}
$$

\section{Experimental results and discussion of studies}

The structure of all the studied steels consisted of perlite and a small amount of cementite (Fig. 1). The beam impact zone of a non-porous U10 steel sample had a pronounced boundary between the sample base and the heat-affected zone. In contrast to the structure of U10 cast steel, in powder steels, the analysis of the microstructure allowed us to subdivide the hardening region into 4 zones (Fig. 1): I — melting zone with reduced porosity, II — melting zone with initial porosity, III — hardening from a solid state zone, zone IV - raw material.

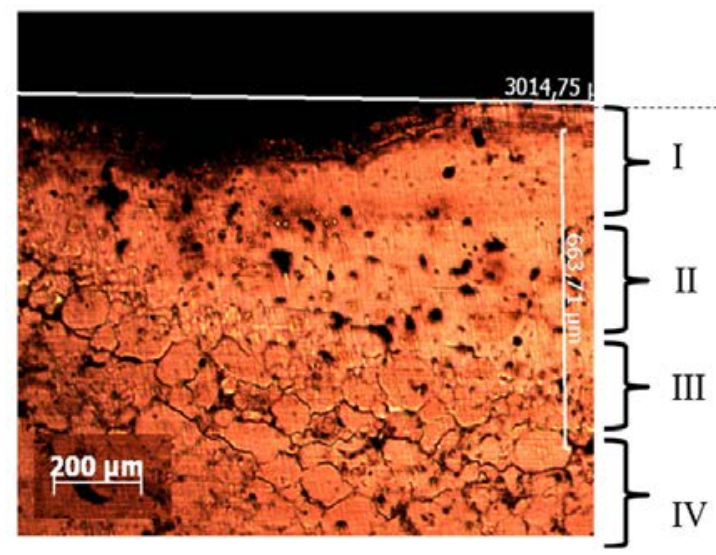

$\underline{\mathrm{a}}$

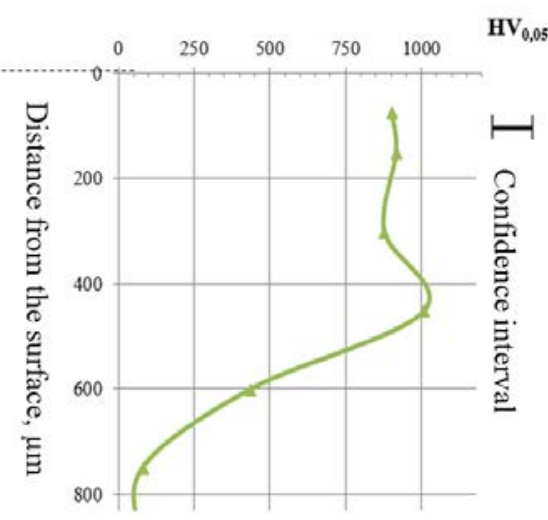

$\underline{\mathrm{b}}$

Fig. 1. The microstructure of the heat-affected zones and their microhardness (PA-ZhGr sample with a porosity of $10 \%$, processed according to the mode $\mathrm{W}=16 \mathrm{~kW} / \mathrm{cm}^{2}, \mathrm{~V}=0.8 \mathrm{~cm} / \mathrm{s}, \mathrm{d}=2 \mathrm{~mm}$ ).

In the melting zone, individual powder particles are not observable. The steel in this zone had a martensitic structure; impregnations of residual austenite were observed in the form of sections with less etchability. The low porosity of the material in this zone is due to shrinkage of pores during liquid-phase compaction and the release of part of the pores to the surface during the existence of the liquid phase. Due to the high speed of the LT process, not all pores from the melting zone have time to reach the surface of the material, and zone II is formed a melting zone with initial porosity. The structure in this zone is also martensitic; the microhardness of the entire melting zone is high, up to $1000 \mathrm{HV}_{0.05}$ (Fig. 1).

The structure of zone III corresponds to the state of quenching from the solid state and is transitional from martensite to perlite with a cementite mesh with distance from the surface. The microhardness in this zone gradually decreases to the microhardness of the base material, zone IV.

Microhardness measurements over the depth of the heat-affected zone made it possible to compare the depth of the hardened layer for various materials. The microhardness of the surface layer was practically independent of the porosity of the samples due to the fact that 
with the same chemical composition on the surface in all cases a non-porous martensitic layer forms. But with an increase in porosity, an increase in the hardening zone is observed, associated with a lower value of the thermal conductivity of the material and the deterioration of the conditions of heat removal to the main material, due to which the samples are mainly cooled.

The technological modes of LT had a noticeable effect on the characteristics of the treated layer. After statistical processing of the results of a full factorial experiment, polynomials were obtained for the dependences of the hardening depth (h) and microhardness (HV) on the LT parameters for samples of different porosity. The microhardness polynomial of samples with a porosity of $4 \%$ with a laser beam diameter of $2 \mathrm{~mm}$ :

$$
H V_{0.05}=480+252 x_{1}-42 x_{2}+41 x_{1} x_{2}-62 x_{1}^{2}+157 x_{2}^{2},
$$

where $\mathrm{x}_{1}$ is the power density of the laser radiation, $\mathrm{x}_{2}$ is the laser beam velocity.

The polynomial of the depth of the hardened layer of samples with a porosity of $4 \%$ with a laser beam diameter of $2 \mathrm{~mm}$ :

$$
h=417+150 x_{1}-50 x_{2}+50 x_{1}^{2}-100 x_{2}^{2}
$$

Polynomials are presented in encoded form for the convenience of assessing the influence of factors on response functions.

It was found that the power density of laser radiation has an almost directly proportional effect on microhardness and on the thickness of the treated layer. The dependences of the microhardness and the thickness of the hardened layer on the velocity of the laser beam have the form of parabolas with extrema in the studied range of factors. This allows us to optimize the LT modes and adjust the characteristics of the surface layer. Figures $2 \mathrm{a}$ and $2 \mathrm{~b}$ show the response surfaces for polynomials (4) and (5), respectively.

\section{Response surface for Microhardness}

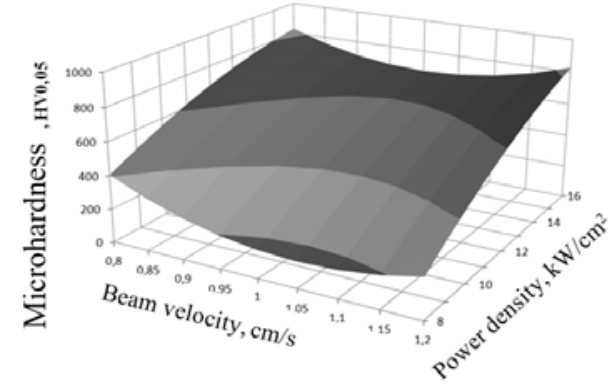

a

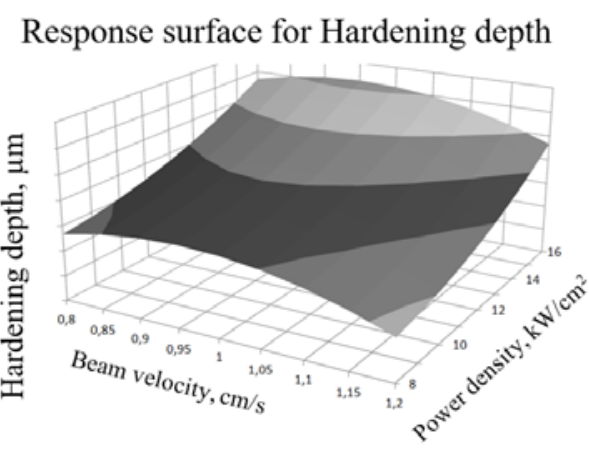

b

Fig. 2. Response surfaces constructed from regression polynomials a) microhardness, b) depth of the hardened layer.

During the laser treatment of porous samples, in some cases, it is possible to form cracks around the heat-affected zone passing along the grain boundaries, which negatively affects the strength characteristics of the surface up to the separation of the treated area from the base material.

The crack formation can be caused by the thermal shrinkage of the melt pool during surface melting, thermal stresses at the phase boundary, and also the condensation of pores 
at the thermal impact boundary, therefore, the processing modes for cast products are not always applicable to porous steels.

The effect of the porosity of powder steels on the boundary values of the LT parameters providing an increase the surface microhardness without cracking in the subsurface zone was studied (Fig. 3). It has been established that for cast steel U10 LT can be treated with any combination of modes without the risk of cracking. Studies of powder steels have shown that, depending on the porosity, the parameter should not exceed 0.4 for porosity $4 \%, 0.32$ for porosity $8 \%$ and 0.24 for porosity $10 \%$.

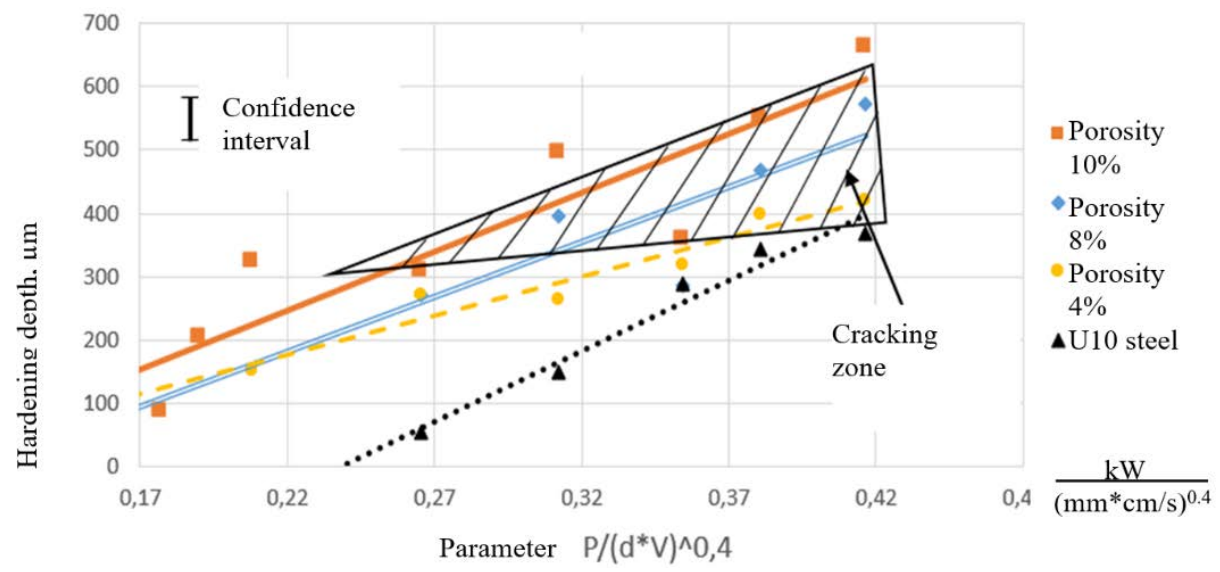

Fig. 3. Dependence of LT modes on the hardening depth of steels, PA-ZhGr and U10, laser spot diameter $2 \mathrm{~mm}$.

\section{Laser process modelling}

The interaction of laser radiation with opaque solids can be conditionally divided into several stages, including the absorption of part of the laser radiation by the surface, the propagation of heat from the surface into the interior of the material, the absorption or release of heat during phase transitions, heating the substance in another phase state; when the laser beam ceases, the process proceeds in the reverse order.

Based on the assumptions made, the heat equation can be reduced to the thermal equation of the two-phase zone model:

$$
\Psi(T) \frac{\partial T}{\partial t}=a\left(\varepsilon_{V}, \varepsilon_{\sigma}\right) \nabla^{2} T+F\left(q_{L}\right),
$$

where $\Psi$ is the dimensionless effective heat capacity considering the release of the latent heat of the phase transition; $\mathrm{T}$ is the absolute temperature, $\mathrm{t}$ is time, $a$ is the thermal diffusivity, $\varepsilon_{\mathrm{V}}$ and $\varepsilon_{\sigma}$ are the porosity characteristics of the composite steel matrix, defined as the volume fraction of pores and the fraction of pores in a flat section, respectively, $F=\alpha q_{L}$ is the intensity of the volume heat source associated with the power of the laser irradiation at different depths; $\alpha$ - the absorption coefficient of light radiation; $\mathrm{q}_{\mathrm{L}}$ - the laser flux density. The coefficient $\alpha$ depends both on the temperature and the phase composition of the local volume, determining in the model the change in the depth of penetration of laser radiation during the melting of the surface layer. 
The calculations were performed in the software of engineering calculations COMSOL Multiphysics using the finite element method. For the simulation, the "Heat Transfer in Solids” module was used, which includes the following elements: Boundary Heat Source (heat flux of laser radiation), Heat Flux (heat flux of convective cooling of the surface), Thermal insulation, Open Boundary, Diffuse Surface (heat dissipation through radiation), Phase change (phase transformations).

The geometry of the computational domain was specified in a two-dimensional form, axisymmetric, and simulated the transit of a laser beam of a given power and its distribution over the beam area over the surface of the material at a given speed. The calculation result for the given LT modes (corresponding to the experimental conditions) is a picture of the distribution of thermal fields over the cross section of the ring sample (Figure 4). Zone I corresponds to the zone of complete melting of the material, zone II corresponds to the zone of quenching from the solid state, zone III corresponds to the material in the initial state.

The calculation model also allows us to determine the rate of change of temperature in the LT area. According to the calculation, the cooling rate on the surface of the material exceeds $7000{ }^{\circ} \mathrm{C} / \mathrm{s}$, which is significantly higher than the speed required for martensitic transformation.

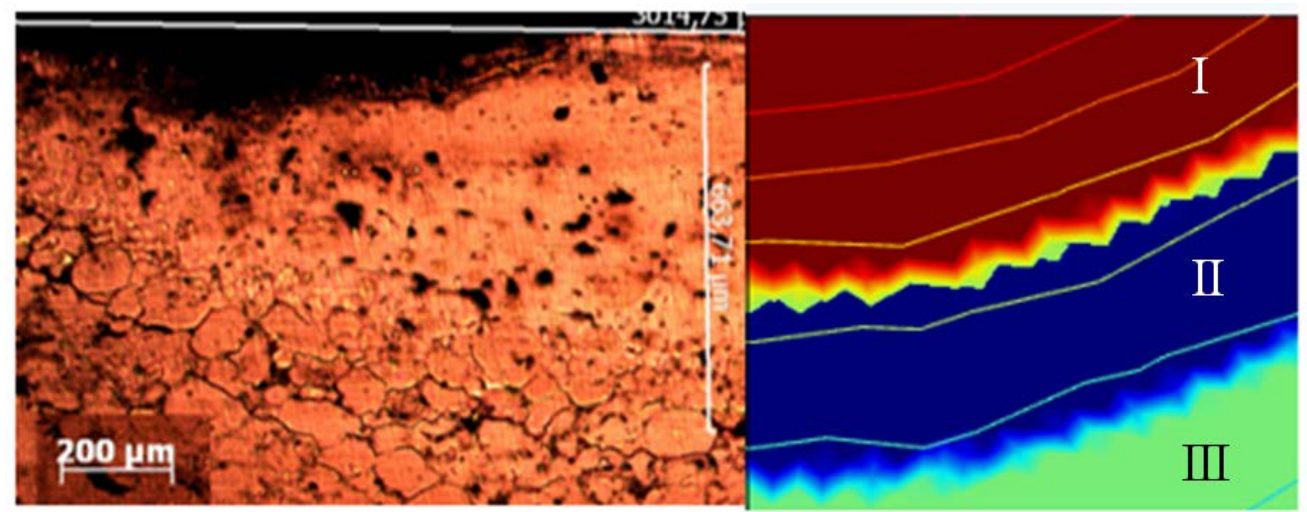

Fig. 4. Microstructure of PA-ZhGr steel after LT (left) and calculated zones of phase distribution (right).

\section{Conclusion}

As a result of the studies, it was found that with an increase of the porosity of powder carbon steels, the geometric parameters of the heat-affected zone increase. Porosity does not affect the microhardness of the surface layer, which can reach $900-1000 \mathrm{HV}_{0.05}$, however, it affects the depth of hardening, for example, hardening occurs at a greater depth at a lower porosity, and for a cast sample U10, the depth of hardening corresponds to the depth of the heat affected zone. An integral parameter of laser processing modes is proposed and boundary values of the parameter are determined at which a crack does not form in porous steels, which worsens the surface strength properties. The results of metallographic analysis with sufficient accuracy coincide with the calculated geometric and temperature parameters of the laser exposure zones, which indicates the correct formulation of the thermal problem. The model could be used to predict the results of LT of the studied steels. 


\section{References}

1. A.G. Grigor'yanc, I.N. Shiganov, A.I. Misyurov, Technological processes of laser treatment, (2006)

2. G. A. Mishakov, A. I. Rodinov, A.M. Myasnikov, Integrated chemical-thermal and laser processing of structural and tool steels, Vestnik NIYaU MIFI, 1, 11, (2014)

3. V. I. Mosorov, A.M. Gur'ev, B.D. Lygdenov, D.S. Fil'chakov, Surface hardening of cast steel by complex diffusion saturation with boron and chromium, Obrabotka metallov, 2. 33, (2011)

4. A.A. Hubathuzin, I.Sh. Abdullin, A.A. Bashkircev, E.B. Gatina, The use of plasma methods for surface modification of metals, Vestnik Kazanskogo tekhnologicheskogo universiteta, 22, 48, (2012)

5. Yu.A. Balandina, Hardening of the surface of die steels by diffusion boronation, boron plating and borochroming in the fluidized bed// Metallovedenie i termicheskaya obrabotka metallov, 597, 27, (2005)

6. Yu. F. Ivanov, V.E. Gromov, O.A. Kondratova, E. G. Belov, V.B. Kosterov, The formation of the mechanical properties of the surface of low-carbon steel during thermomechanical hardening, Obrabotka metallov, 2, 38, (2017)

7. A.N. Safonov, Structure and microhardness of the surface layers of iron-carbon alloys after laser hardening, Metallovedenie i termicheskaya obrabotka metallov, 2, 20, (1996)

8. P. A. Ogin, D. L. Merson, S. I. Yares'ko, Influence of laser radiation power and beam velocity on the geometry of the fusion zone during laser hardening of 40Cr steel, Vektor nauki TGU, 2, 46, (2016)

9. E. S. Belyaev, E. V. Tumina, T. V. Makarov, Geometric characteristics of the heataffected zone during laser processing of 38CrNi3MoVAl steel, Theoretical \& Applied science, 1, 153, (2017)

10. L. G. Petrova, O. V. Chudinova, Modeling hardening in the development of technologies for modifying the surface of steel using laser heating, Vestnik MADGTU, 7, 22, (2006)

11. A.G. Grigor'yanc, N.A. Smirnova, Hardening of the surface of steel 45 and cast aluminum alloy AK9 by radiation of a fiber laser, Tekhnologiya mashinostroeniya, 11, 52, (2011)

12. V. D. Aleksandrov, Modification of the surface of aluminum alloys by laser processing, Metallovedenie i termicheskaya obrabotka metallov, 4, 33, (2002)

13. V. Biryukov, Modifocations in the structure and properties of steels during laser hardening, Photonika, 3, 22, (2012)

14. N.K. Tolochko, Laser applications in powder metallurgy, Fizika i himiya obrabotki materialov, 1, 94, (1995)

15. T.P. Nino, The wear resistance of porous coatings (sintering by laser radiation of powder compositions on the surface of worn parts), Inzhenerno-tekhnicheskoe obespechenie APK. Referativnyj zhurnal, 4, 1187, (2010) 
16. S.P. Yurkevich, A.V. Tomashevich, A.S. Yurkevich, Repair of aircraft parts by laser cladding, Remont. Vosstanovlenie. Modernizaciya, 3, 31, (2006)

17. V.N. Petrovskij, V.G. Shtamm, P.S. Dzhumaev, V.I. Pol'skij, Laser surfacing of metal powders, Yadernaya fizika i inzhiniring, 4, 333, (2012)

18. V.G. Gilev, N.V. Bezmaternyh, E.A. Morozov, E.S. Rusin, Traits of laser hardening of ring bearings made of a steel-copper pseudo-alloy, Izvestiya Samarskogo nauchnogo centra Rossijskoj akademii nauk, 4, 179, (2014)

19. E.S. Belyaev, S. S. Dudyreva, N. V. Makarov, Effect of laser processing on the geometric dimensions of the melting zones and thermal influence during the processing of sintered porous iron, Teoreticheskaya i prikladnaya nauka, 2, 143, (2017)

20. Yu. D. Grigor'ev, Methods of optimal experimental design: linear models: a Training manual, (2015) 